\title{
Magazine 4.0
}

\section{Dear Reader,}

The term Industry 4.0 is currently on everyone's lips. It is not only OEMs, suppliers and development service providers who are changing with the internet and need to reorient themselves. Publishing houses are also in a fundamental process of change, and we at Springer Nature want to play an active role in shaping this development. For that reason, ATZ and its sister magazines have been available to our English-speaking subscribers as a state-of-the-art digital magazine since the beginning of this year. And from February onwards, readers of our German magazine will also have access to it as an interactive E-magazine.

The digital magazine world opens up new perspectives, not only for us in the editorial team by providing more freedom in content and design, but also for you as the reader by offering a new magazine experience. Additional images, technical animations and videos create genuine added value. Deep links on our knowledge and corporate pages provide further information and round off our articles.

As usual, this issue of ATZ once again includes strong cover stories, opened by Daimler with its high-resolution 84-pixel multibeam headlamp system from the E-Class. Equally interesting and groundbreaking is the report on the new IntelliLux LED matrix headlight on the new Opel Astra. Also on the subject of lighting technology, the report by Edag describes new degrees of freedom in headlight development by applying bionic design and generative manufacturing processes. Typical of the wide range of subjects in an ATZ issue is the article by ika on a concept vehicle with an electric in-wheel drive system. And you can also look forward to our report on data management and cloud computing in the run-up to the $2^{\text {nd }}$ International ATZ Conference Driver Assistance Systems on 13 and 14 April in Frankfurt am Main.

I hope you enjoy your digital ATZ.

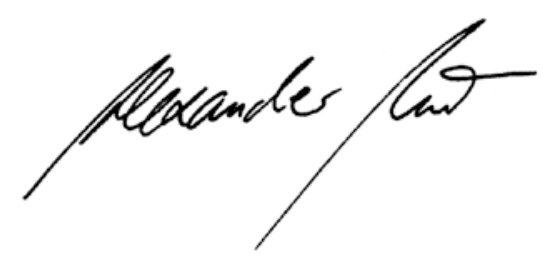

Dr. Alexander Heintzel Editor in Chief

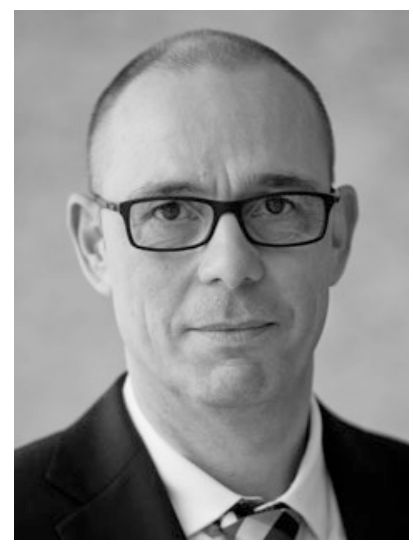

